\title{
Modeling the Dynamic Recrystallization of Mg-11Gd-4Y-2Zn-0.4Zr Alloy Considering Non-uniform Deformation and LPSO Kinking During Hot Compression
}

\author{
Hong-Xuan Zhang ${ }^{1,2} \cdot$ Shuai-Feng Chen ${ }^{1} \cdot$ Ming Cheng $^{1} \cdot$ Ce Zheng ${ }^{1,3} \cdot$ Shi-Hong Zhang ${ }^{1}$
}

Received: 30 November 2018 / Revised: 14 January 2019 / Published online: 16 April 2019

(c) The Chinese Society for Metals (CSM) and Springer-Verlag GmbH Germany, part of Springer Nature 2019

\begin{abstract}
Hot compression tests of $\mathrm{Mg}-11 \mathrm{Gd}-4 \mathrm{Y}-2 \mathrm{Zn}-0.4 \mathrm{Zr}$ alloy (GWZK114) were conducted at a deformation temperature range of $300-500{ }^{\circ} \mathrm{C}$ and a strain rate range of $0.01-10.0 \mathrm{~s}^{-1}$. Based on systematic microstructure observation, it is confirmed that long period stacking ordered (LPSO) phase displays essential and evolving roles on the dynamic recrystallization (DRX) behavior. The results indicate that the plastic deformation is mainly coordinated by simultaneous exist of LPSO kinking of lamella $14 \mathrm{H}-\mathrm{LPSO}$ phase and DRX at $350-450{ }^{\circ} \mathrm{C}$, and DRX at $500{ }^{\circ} \mathrm{C}$. Further, it is found that the LPSO kinking induced during $350-450{ }^{\circ} \mathrm{C}$ can delay the DRX. A phenomenological DRX model of GWZK114 alloy is established to be $X_{\mathrm{DRX}}=1-\exp \left[-0.5\left(\frac{\varepsilon-\varepsilon_{\mathrm{c}}}{\varepsilon^{*}}\right)^{0.91}\right]$. Non-uniform distribution of plastic strain during compression was considered via finite element method and it ensures a good prediction of DRX fraction under a large plastic strain. Meanwhile, an enhanced DRX model, taking its formulation as $X_{\mathrm{DRX}}=\left\{1-\exp \left[-0.5\left(\frac{\varepsilon-\varepsilon_{c}}{\varepsilon^{*}}\right)^{0.91}\right]\right\}\left(\frac{T}{226.8}-1\right)^{n}, n=3.82 \dot{\varepsilon}^{0.083}$, is proposed for the first time to capture the hindering effect of 14H-LPSO kinking on DRX behavior. The predicted results of this enhanced DRX model agree well with the experimental cases, where $14 \mathrm{H}$-LPSO kinking is dominated or partially involved $\left(300-450{ }^{\circ} \mathrm{C}\right)$. Besides, a size model of DRX grains is also established and can depict the evolution of DRX grain size for all the investigated compression conditions with accounting for temperature rising at high strain rates $\left(5 \mathrm{~s}^{-1}\right.$ and $\left.10 \mathrm{~s}^{-1}\right)$.
\end{abstract}

Keywords Mg-11Gd-4Y-2Zn-0.4Zr alloy $\cdot$ Modeling $\cdot$ Dynamic recrystallization $\cdot$ Non-uniform strain $\cdot$ LPSO kinking

\section{Introduction}

Wrought magnesium alloy is treated as the most potential lightweight structure materials for its low density, high specific strength and good damping property [1]. In particular, magnesium alloys containing rare earth (RE) are attracting more and more attention in recent years attributed to their good combination of strength and toughness [2]. Among

Available online at http://link.springer.com/journal/40195

Ming Cheng

mcheng@imr.ac.cn

1 Institute of Metal Research, Chinese Academy of Sciences, Shenyang 110016, China

2 School of Materials Science and Engineering, University of Science and Technology of China, Shenyang 110016, China

3 University of Chinese Academy of Sciences, Beijing 100049, China these magnesium alloys, LPSO phases are usually metallurgy formed in Mg-TM (transition metal)-RE (rare earth) alloys, such as $\mathrm{Mg}-\mathrm{Zn}-\mathrm{Y}$ [3], $\mathrm{Mg}-\mathrm{Zn}-\mathrm{Gd}, \mathrm{Mg}-\mathrm{Zn}-\mathrm{Gd}-\mathrm{Y}$ $[4,5]$ and $\mathrm{Mg}-\mathrm{Y}-\mathrm{Cu}[6]$. During deformation, LPSO phases can act as strengthening phases through a fiber reinforcement mechanism [7]. Moreover, kinking of LPSO phase was always induced by the plentiful activation of basal slip $\langle a\rangle$ and absence of non-basal slips owing to its complex crystallographic structure [8]. Formation of kink band attributed to repeated kinking of LPSO phase can be treated as an effective deformation mode for the release of stress accumulation [9].

At elevated temperatures, the interactions between LPSO phase and DRX behavior have been widely studied. Onorbe et al. [10] investigated the DRX behavior of $\mathrm{Mg}-\mathrm{Y}-\mathrm{Zn}$ alloy and shows that nucleation of DRX at the interface between matrix and intergranular 18R-LPSO phase can be promoted through Particle Stimulation Nucleation mechanism (PSN). Additionally, Xu et al. [11] revealed that grain refinement due to PSN can also be introduced by intragranular lamella-shaped 
14H-LPSO phase inside Mg-Gd-Y-Zn-Zr alloy. However, Zhang et al. [12] augured that the DRX can be restricted by an over-dense intragranular LPSO phase. Also, a similar restrained effect on DRX is also found by Lv et al. [13] at low temperature $\left(300-350^{\circ} \mathrm{C}\right)$. Given the aforementioned discussion, the LPSO phase presents a comprehensive and essential role in the DRX behavior of LPSO-contained magnesium alloys.

On the other hand, it is believed that mechanical properties of magnesium alloys are closely related to their grain size and texture features [14-16]. Moreover, the control of grain size is mainly realized by adjusting the DRX fraction and size of DRX grains during thermal-mechanical processing, such as rolling [17], extrusion [18]. To predict the DRX fraction during thermal deformation, phenomenological DRX models based on the Avrami type equations are widely used owing to its simple formulations and less parameter dependence [19-22]. The main parameters of these models are obtained using inflection point method, where elevated compression tests are conventionally adopted to capture the strain hardening behavior of material [23, 24]. DRX models for magnesium alloys contained LPSO phase, $\mathrm{Mg}-2.0 \mathrm{Zn}-0.3 \mathrm{Zr}-5.8 \mathrm{Y}[13,25]$ and $\mathrm{Mg}-12 \mathrm{Gd}-4.5 \mathrm{Y}-2 \mathrm{Zn}-0.4 \mathrm{Zr}$ [26] have been established by the inflection point method. According to the prediction of these models, fully recrystallized microstructure can be prospected at a strain of 1.0 at both $420^{\circ} \mathrm{C}$ and $500{ }^{\circ} \mathrm{C}$. Unfortunately, these predictions display an obvious discrepancy with experimental observation, such as repetitive upsetting-extrusion (RUE) preformed on $\mathrm{Mg}-12.0 \mathrm{Gd}-4.5 \mathrm{Y}-2.0 \mathrm{Zn}-0.4 \mathrm{Zr}$ $[27,28]$. The DRX fraction was just $45.5 \%$ for $420{ }^{\circ} \mathrm{C}$ and $65.8 \%$ for $500{ }^{\circ} \mathrm{C}$ under an accumulated strain of 4.05 . One reason for this contradiction should be originated from nonuniform strain during compression induced by the inevitable friction between ram and specimen. Another probable reason is the lacking consideration of hindering effect of LPSO phase on DRX behavior. To date, non-uniform strain and effect of LPSO kinking are still rarely modeled for LPSO-contained magnesium alloys.

In this study, hot compression tests were carried out on ashomogenized GWZK114 alloy with intergranular 18R-LPSO phases and intragranular 14H-LPSO phases. Special attention were paid to the effect of LPSO kinking on the DRX behaviors. Both the effects of non-uniform strain during compression and LPSO kinking on evolution of DRX fraction are well integrated into a phenomenological DRX model. Meanwhile, a model with good prediction of DRX grain size was also established.

\section{Experimental Procedures}

A cast ingot bar of GWZK114 alloy was produced by direct chill casting with its diameter being $300 \mathrm{~mm}$ and length being $650 \mathrm{~mm}$. The actual chemical compositions of GWZK114 are

listed in Table 1, which are very close to the nominal compositions, $\mathrm{Mg}-11 \mathrm{Gd}-4 \mathrm{Y}-2 \mathrm{Zn}-0.4 \mathrm{Zr}$ (wt\%). Specimens cut from the ingot were homogenized at $500{ }^{\circ} \mathrm{C}$ for $16 \mathrm{~h}$ with a resistance furnace and cooled to the room temperature in air.

The homogenized specimens were machined into cylinders with $8 \mathrm{~mm}$ in diameter and $12 \mathrm{~mm}$ in height. Then isothermal compression tests were performed by Gleeble- 3800 machine. Before compression, graphite sheets were used to reduce the friction between cam and cylinder ends. During compression, the cylinders were firstly heated to designed temperatures with a rate of $5{ }^{\circ} \mathrm{C} \mathrm{s}^{-1}$ and held for $300 \mathrm{~s}$ and followed by compressing to a true strain of 0.8 with the height reduction being $55 \%$. The designed temperature and strain rate are $300{ }^{\circ} \mathrm{C}, 350{ }^{\circ} \mathrm{C}$, $400{ }^{\circ} \mathrm{C}, 450{ }^{\circ} \mathrm{C}$ and $500{ }^{\circ} \mathrm{C}$ and $0.01 \mathrm{~s}^{-1}, 0.1 \mathrm{~s}^{-1}, 1 \mathrm{~s}^{-1}, 10 \mathrm{~s}^{-1}$, respectively. To obtain the DRX fraction under different strain levels, compressive strains of $0.2,0.4,0.6,0.8$ and 1.2 were imposed to specimens, respectively, at a fixed temperature of $450{ }^{\circ} \mathrm{C}$ with strain rates of $0.01 \mathrm{~s}^{-1}$ and $1 \mathrm{~s}^{-1}$. Additionally, compressions with a true stain of 0.8 were carried out at strain rate of $0.01 \mathrm{~s}^{-1}, 0.1 \mathrm{~s}^{-1}, 1 \mathrm{~s}^{-1}$ for $480^{\circ} \mathrm{C}$ and $5 \mathrm{~s}^{-1}$ for $400^{\circ} \mathrm{C}$, $450{ }^{\circ} \mathrm{C}, 480{ }^{\circ} \mathrm{C}$ to provide enough data for further model validation. All the compressed cylinders were water quenched to retain their DRX features after hot compression.

Several charactering measures were adopted to observe the microstructure. Samples were mechanically ground by SiC abrasive papers (800\#, 1200\# and 2000\#), and polished sequentially. ZEISS Z1 m Optical microscope (OM) was carried out on samples etched with an acetic picral etchant $(4.8 \mathrm{~g}$ picric acid, $10 \mathrm{ml}$ glacial acetic acid, $10 \mathrm{ml}$ distilled water and $70 \mathrm{ml}$ alcohol). More features of microstructure were examined by Hitachi S3400N scanning electron microscope (SEM) equipped with energy dispersive spectrometer (EDS) and FEI Tecnai G2 F20 transmission electron microscopy (TEM). Characteristics of DRX behavior were studied in detail by electron backscattered diffraction (EBSD) on ZEISS Merlin compact. Besides, micro-hardness tests were also conducted on a hardness test machine, LM247 ${ }_{\mathrm{AT}}$, with loading as $100 \mathrm{~N}$ and holding time as $15 \mathrm{~s}$. It is noted that all microstructure observations are performed on the center region of deformed cylinders if it is not especially stressed.

In order to quantify the DRX fraction and grain size, DRX gains were statistically marked out on OM images by image analysis software, Image Pro-plus 6.0 [29]. Meanwhile, DRX fractions were also analyzed by EBSD with HKL channel 5.0, where grains with GOS (Grain Orientation Spread) less than $2^{\circ}$ could be treated as DRX grains [30].

Table 1 Chemical compositions of GWZK114 (wt \%)

\begin{tabular}{lllll}
\hline $\mathrm{Gd}$ & $\mathrm{Y}$ & $\mathrm{Zn}$ & $\mathrm{Zr}$ & $\mathrm{Mg}$ \\
\hline 10.8 & 3.93 & 1.94 & 0.37 & $\mathrm{Bal}$. \\
\hline
\end{tabular}




\section{Results and Discussion}

\subsection{Microstructure and Phase Characterization Before Compression}

Figure 1 shows the microstructure of as-casted and ashomogenized GWZK114 alloy before compression. The OM image in Fig. 1a indicates the casted microstructure mainly contains $\alpha-\mathrm{Mg}$, intragranular phase with lamellar shape, intergranular phase with block shape and eutectic phase. Based on the careful identification by TEM, it is confirmed that the intergranular phase is well-formed 18R-LPSO (Fig. 1b), whereas the intragranular phase is partially formed 14H-LPSO inside wide solute-segregated stacking faults (SFs). After homogenization, the fraction of eutectic phase greatly decreased in Fig. 1d with 18R-LSPO phase being well retained (Fig. 1e). Simultaneously, 14H-LPSO phase (Fig. 1f) is well structured through absorbing the rare earth elements of dissolved eutectic phase. The statistical fractions of magnesium matrix, 18R-LPSO phase and residual eutectic phase are $86.19 \%, 11.63 \%$ and $2.18 \%$, respectively.
Figure 2 displays the SEM images of different phases and their corresponding micro-hardness. The chemical compositions of phases marked by A, B and C in Fig. 2a were analyzed by EDS. The results reveal that $\alpha-\operatorname{Mg}$ (Point A) is $\mathrm{Mg}_{96} \mathrm{Gd}_{2} \mathrm{Y}_{1} \mathrm{Zn}_{0.4}$ (at\%), 18R-LPSO phase (Point B) is $\mathrm{Mg}_{85.61} \mathrm{Gd}_{5.01} \mathrm{Y}_{3.31} \mathrm{Zn}_{5.99} \mathrm{Zr}_{0.1}$ (at\%) and eutectic phase (Point C) is $\mathrm{Mg}_{81.67} \mathrm{Gd}_{11.33} \mathrm{Y}_{4.34} \mathrm{Zn}_{2.48} \mathrm{Zr}_{0.17}$ (at\%). As given in Fig. 2b, the micro-hardness of 18R-LPSO phase and 18R-LPSO with eutectic phase is $104.6 \mathrm{HV}$ and 122.7 HV, respectively, They are $48 \%$ and $74 \%$ higher than that of matrix composed of $\alpha-\mathrm{Mg}$ with $14 \mathrm{H}-\mathrm{LPSO}$ (70.7HV) meaning that $18 \mathrm{R}$-LPSO and eutectic phase possesses much higher strength.

\subsection{Microstructure Evolution After Compression}

Figure 3 gives OM microstructure of GWZK 114 alloy compressed under different compression temperatures at $0.1 \mathrm{~s}^{-1}$. At $350{ }^{\circ} \mathrm{C}$ (Fig. 3a), few of DRX grains with extremely fine size are induced at grain boundaries (GBs) and the interface between matrixes and block-shaped phase. Besides, severe kinking of lamellar 14H-LPSO phases results in the
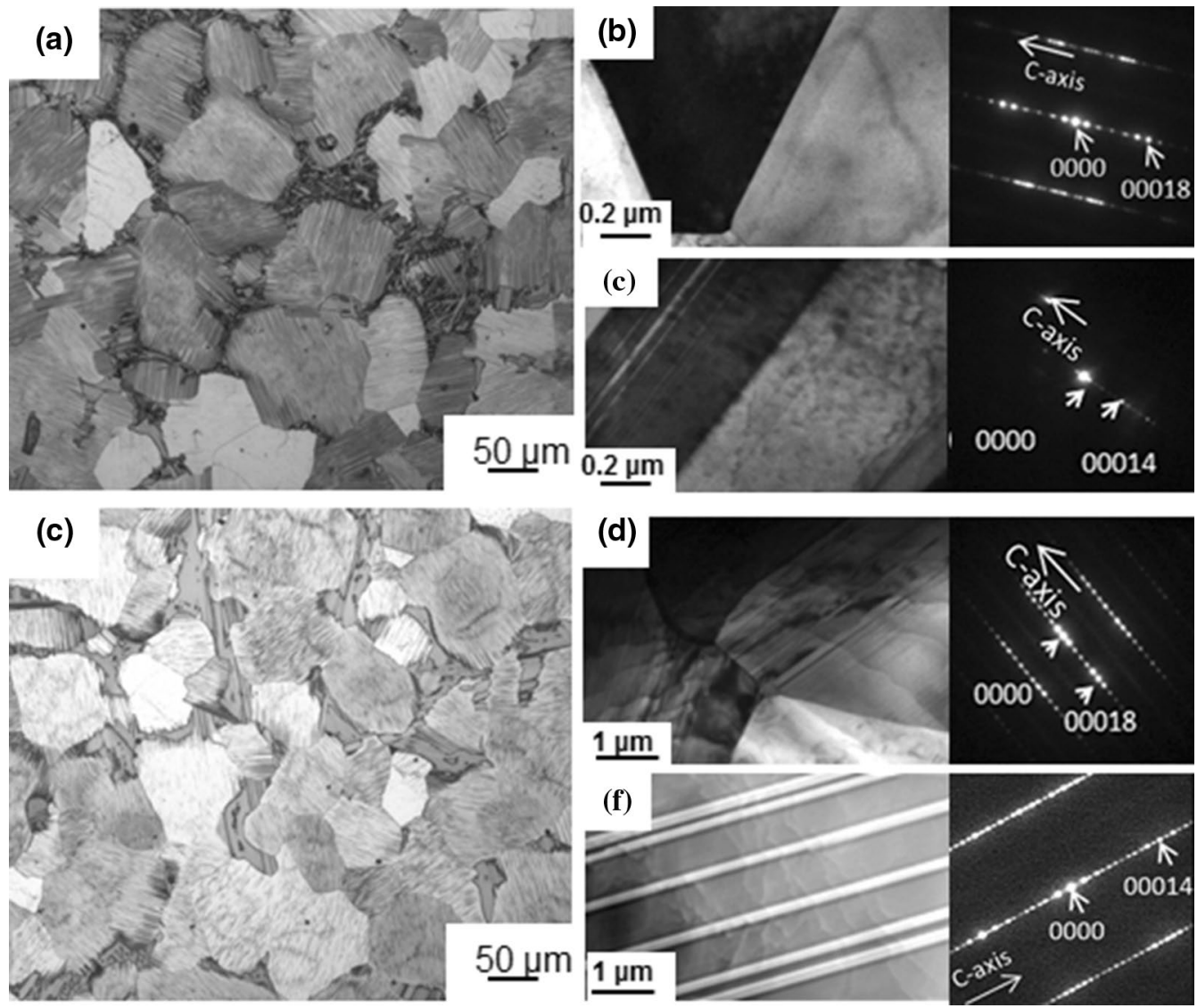

Fig. 1 Microstructure of as-casted specimen: a OM image; TEM images of $\mathbf{b}$ intergranular phase, $\mathbf{c}$ intragranular phase, with their SAED patterns shown at the right side; as-homogenized specimen: $\mathbf{d}$ OM image; TEM images of $\mathbf{e}$ intergranular phase, $\mathbf{f}$ intragranular phase, with their SAED patterns shown at the right side 

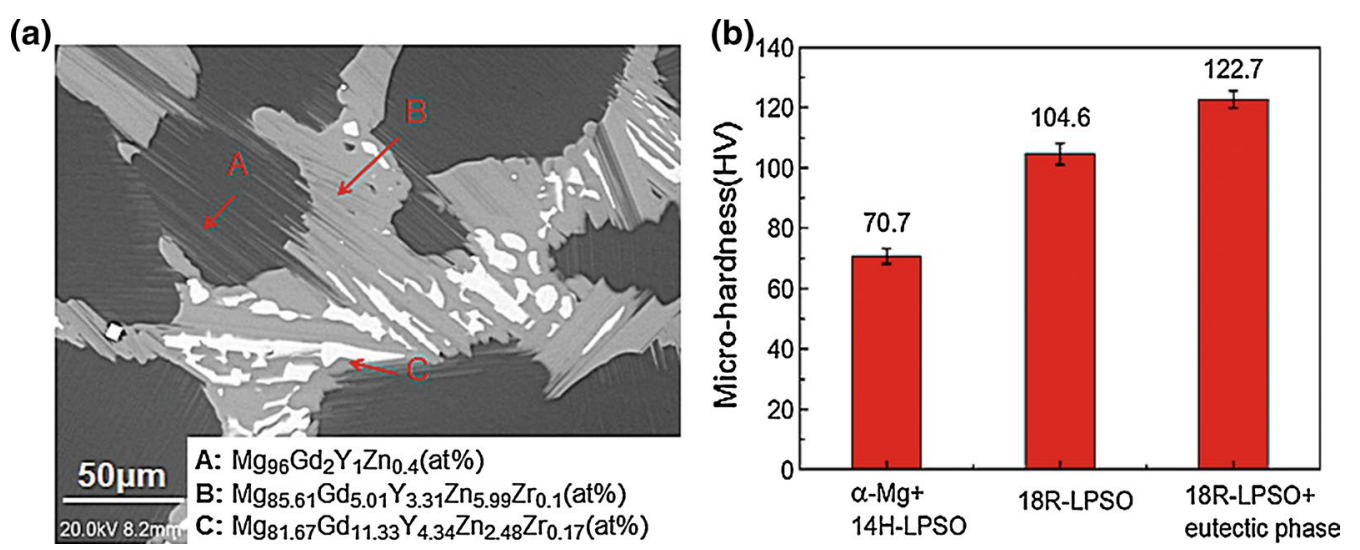

Fig. 2 a SEM image of as-homogenized GWZK114; b micro-hardness of different phases

formation of kink bands inside matrixes. When the deformation temperature increases to $400{ }^{\circ} \mathrm{C}$, more DRX grains are detected at the same locations with a higher fraction (Fig. 3b). Kink bands still widely exist but exhibit a lower kinking angle. As shown in Fig. 3c, DRX fraction at $450{ }^{\circ} \mathrm{C}$ is further enlarged with some matrixes being fully recrystallized. Although formation of kink bands happens, the 14H-LPSO phase inside kink bands just presents slight kinking. At the temperature of $500{ }^{\circ} \mathrm{C}, \mathrm{DRX}$ behavior is well preformed with a much larger size of DRX grains. Moreover, it is detected that $14 \mathrm{H}-\mathrm{LPSO}$ phase inside matrix is no longer kinked. Another interesting observation worth to be mentioned is that the intergranular 18R-LPSO phase is rarely kinked during all the deformation temperatures because of its higher strength (Fig. 2b).

The distinctive DRX fractions and kinking angles of lamellar 14H-LPSO extracted from Fig. 3 are quantitatively shown in Fig. 4. The kinking angles of 14H-LPSO phase inside kind bands decrease rapidly from $62.6^{\circ}$ to $7.9^{\circ}$ with temperature increasing from 350 to $450{ }^{\circ} \mathrm{C}$.
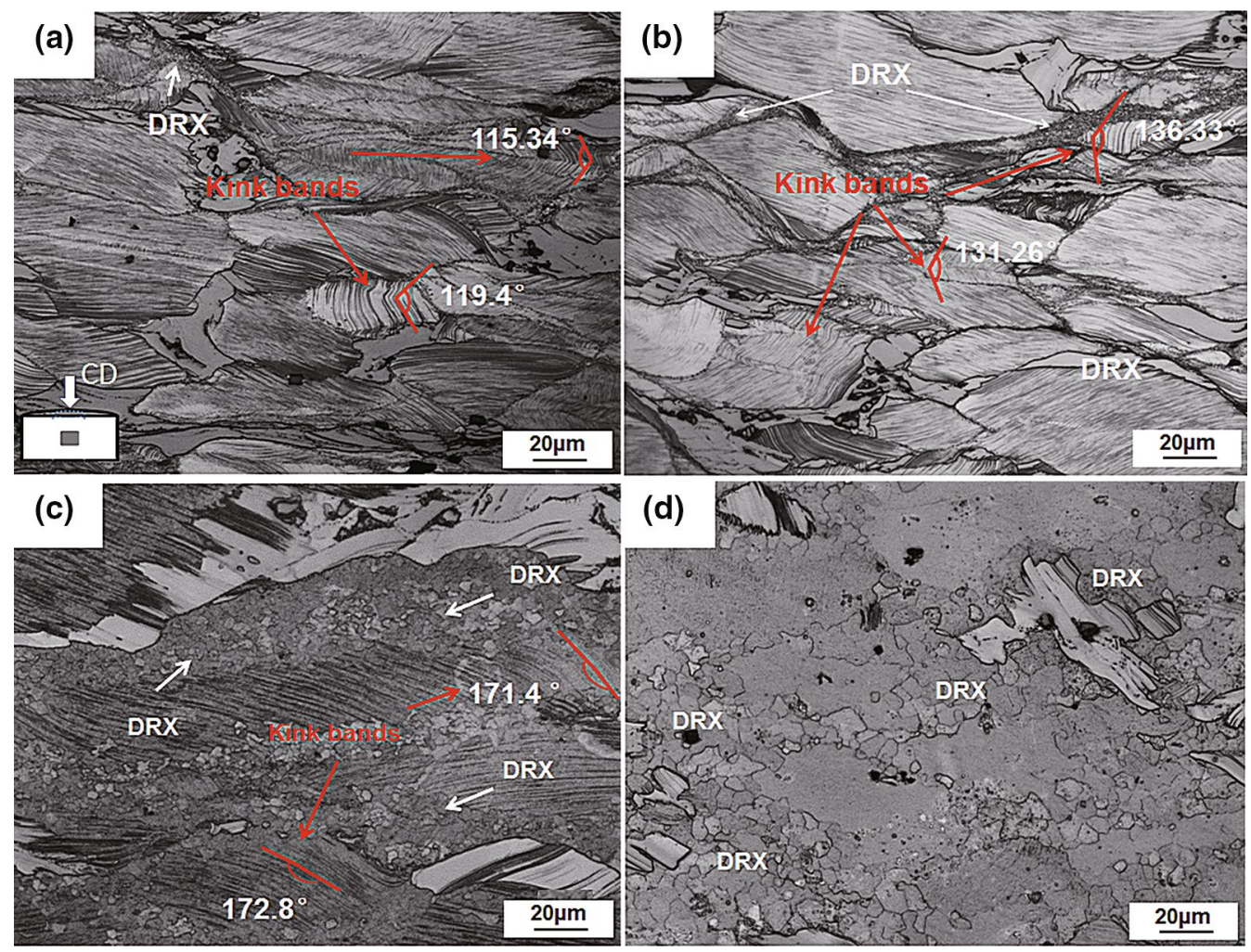

Fig. $3 \mathrm{OM}$ microstructure of samples compressed with a strain rate of $0.1 \mathrm{~s}^{-1}$ at different temperatures: $\mathbf{a} 350{ }^{\circ} \mathrm{C} ; \mathbf{b} 400{ }^{\circ} \mathrm{C} ; \mathbf{c} 450{ }^{\circ} \mathrm{C} ; \mathbf{d} 500{ }^{\circ} \mathrm{C}$ 
Correspondingly, DRX fractions greatly increase from 2 to $39 \%$ with a rising amount of $16 \%$ and $21 \%$ for each temperature interval of $50{ }^{\circ} \mathrm{C}$. However, the DRX fraction at $500{ }^{\circ} \mathrm{C}$ without LPSO kinking is only $50 \%$ with a rising amount of $11 \%$ compared to that of $450{ }^{\circ} \mathrm{C}$. In other words, the DRX kinetics of GWZK 114 alloy at temperature range of $350-450{ }^{\circ} \mathrm{C}$ is not only closely related to deformation temperature but obviously affected by LPSO kinking.

Figure 5 presents EBSD analysis of microstructure under different compressive strains $(0.4,0.8$ and 1.2) at the temperature of $450{ }^{\circ} \mathrm{C}$ and strain rate of $0.01 \mathrm{~s}^{-1}$. At a low compressive strain of 0.4 (Fig. 5a), DRX grains are mainly located at GBs and interface between matrix and 18R-LPSO phase. Also, a limited numbers of DRX grains were detected at inside $\alpha$-Mg matrix (marked by dash circle,

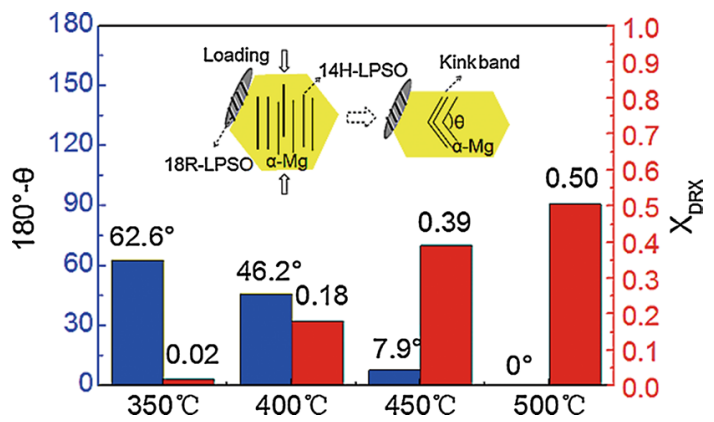

Fig. 4 Kinking angles of 14H-LPSO phase and DRX fractions extracted from Fig. 3 enlarge image shown in Fig. 5d). Similar observation has been reported by $\mathrm{Xu}$ et al. [11]. It was believed that DRX grains at the interface and inside the grain are induced by aforementioned PSN mechanism attributed to block-shaped 18R-LPSO phase and lamellar 14H-LPSO phase. With the strain increasing to 0.8 , the DRX fraction is obviously increased in Fig. 5b. Several matrixes surrounded by blockshaped LPSO phase are totally recrystallized (dash square). The chains of DRX grains induced by 14H-LPSO phase have penetrated whole matrixes marked by arrows (enlarge image shown in Fig. 5e). As shown in Fig. 5c, most of matrices have been recrystallized, especially these at vicinity of 18R-LPSO phases (marked by dash square, enlarge image shown in Fig. 5f).

As shown in result of EBSD test in Fig. 5, both of blockshaped 18R-LPSO phase and lamellar 14H-LPSO phase can promote the DRX behavior at $450{ }^{\circ} \mathrm{C}$. As shown in Figs. $3 \mathrm{c}$ and 4 , the kinking angle at $450{ }^{\circ} \mathrm{C}$ is just $7.9^{\circ}$ indicating that the strain accommodated by LPSO kinking can be neglected under this deformation condition. That is, the promoted effect of 14H-LPSO phase on DRX is mainly prospected for these slightly kinked lamellas, where the $\alpha-\mathrm{Mg}$ matrix could undergo enough plastic strain to stimulate nucleation at the interface with $14 \mathrm{H}$-LPSO phase [12]. However, those larger kinking angles $\left(62.6^{\circ}\right.$ and $\left.26.2^{\circ}\right)$ at $350^{\circ} \mathrm{C}$ and $400{ }^{\circ} \mathrm{C}$ in Fig. 4 suggest that more plastic strain is coordinated by $14 \mathrm{H}-\mathrm{LPSO}$ kinking. This means that the $\alpha-\mathrm{Mg}$ matrixes share less plastic strain leading to a smaller DRX fraction. Thus it is reasonably ascertained that the kinking of
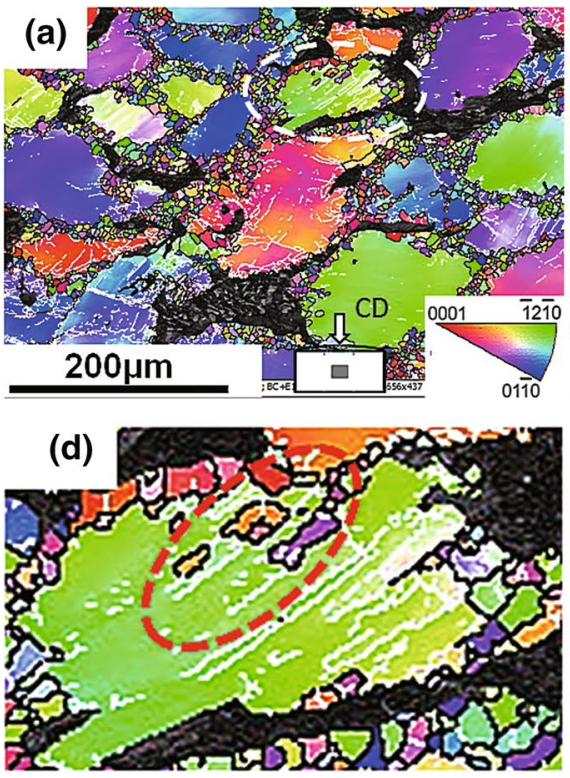
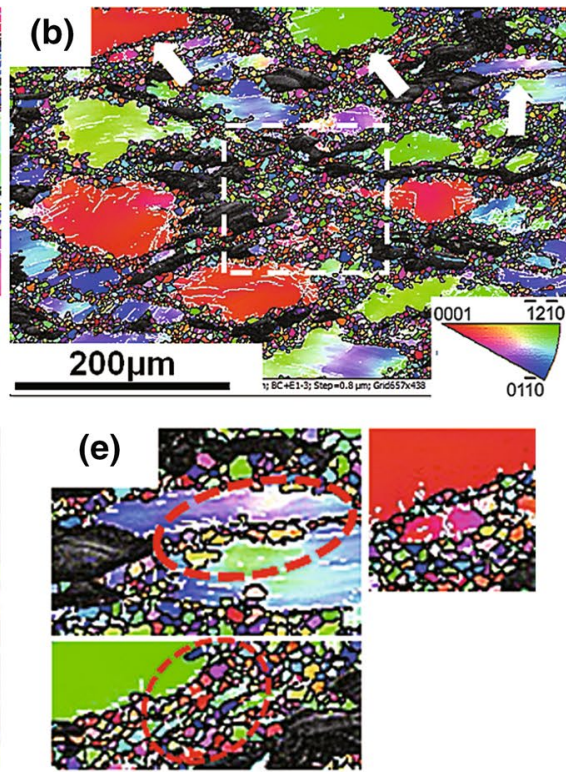
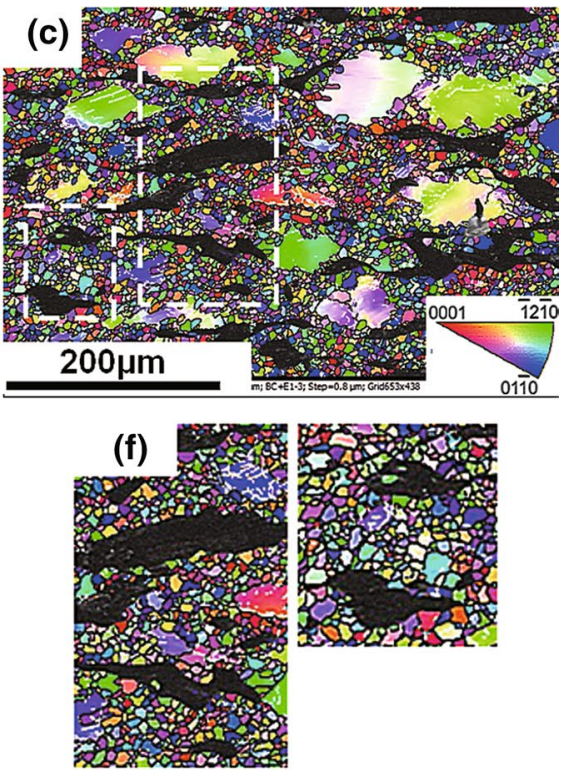

Fig. 5 EBSD analysis of microstructure at the temperature of $450{ }^{\circ} \mathrm{C}$ and strain rate of $0.01 \mathrm{~s}^{-1}$ with compressive strain being a $0.4, \mathbf{b} 0.8, \mathbf{c} 1.2$, $\mathbf{d}$ enlarge image of dash circle shown in $\mathbf{a}$, $\mathbf{e}$ enlarge image of white arrows shown in $\mathbf{b}, \mathbf{f}$ enlarge image of dash square shown in $\mathbf{c}$. The white lines represent low-angle grain boundaries with their misorientation angle between $2^{\circ}$ and $15^{\circ}$, black lines are high-angle boundary with misorientation angle larger than $15^{\circ}$. The black block is the non-indexed intergranular phase 
$14 \mathrm{H}$-LPSO in the temperature range of $350-450{ }^{\circ} \mathrm{C}$ imposes an obvious inhibition on DRX behavior of GWZK114 alloy.

\subsection{Flow Stress and Deformation Activation Energy of Homogenized GWZK 114}

Figure 6 presents the true strain-stress curves of compressed specimens under different temperatures and strain rates. The peak stress is increased under a lower deformation temperature and a higher strain rate. At $300{ }^{\circ} \mathrm{C}$ and a strain rate of $0.1-10 \mathrm{~s}^{-1}$, failure of specimens occurs at a similar strain of 0.46 . Fracture was induced at the interface between matrix and 18R-LPSO phase since incompatible plastic strain is accumulated owing to the absence of DRX grains (OM in Fig. 6b). The same fracture happened to specimen at $350{ }^{\circ} \mathrm{C}$ and $10 \mathrm{~s}^{-1}$ (Fig. 6d). Moreover, specimen at $500{ }^{\circ} \mathrm{C}$ and $10 \mathrm{~s}^{-1}$ is overheated owing to the heat generated by plastic work, which also led to the failure of compression. Although the fractions of DRX are obviously distinctive as shown in Fig. 4, similar softening behaviors are observed in Fig. 6. For instance, the softening stresses, defined as $\sigma_{\text {peak }}-\sigma_{\text {final }}\left(\sigma_{\text {peak }}\right.$ and $\sigma_{\text {final }}$ are peak stress and stress at the final strain), for $350{ }^{\circ} \mathrm{C}$ and $450{ }^{\circ} \mathrm{C}$ are $45 \mathrm{MPa}, 24 \mathrm{MPa}, 32 \mathrm{MPa}$ and $39 \mathrm{MPa}, 29 \mathrm{MPa}, 38 \mathrm{MPa}$ at $0.01 \mathrm{~s}^{-1}, 0.1 \mathrm{~s}^{-1}$ and $1 \mathrm{~s}^{-1}$, respectively. Thus, both of DRX and LPSO kinking of 14H-LPSO phase make contribution to dynamic softening during hot compression.

It is well known that the relationship among strain rate $(\dot{\varepsilon})$, temperature $(T)$ and flow stress $(\sigma)$ can be described by following Arrhenius equation [13, 20]:

$\dot{\varepsilon}=A[\sinh (\alpha \sigma)]^{n} \exp \left(-\frac{Q}{R T}\right)$,

where $Q$ is the deformation activation energy, $R$ is the gas constant $\left(8.3 \mathrm{~J} \mathrm{~mol}^{-1} \mathrm{~K}^{-1}\right), A, \alpha$ and $n$ are material constants. For all the stress levels, Eq. (1) can be expressed by another way as:

$\ln \dot{\varepsilon}=\ln A+n[\ln \sinh (\alpha \sigma)]-\frac{Q}{R T}$.

Generally, two modificated formulations are adopted for the high $(\alpha \sigma>1.2)$ and low $(\alpha \sigma<0.8)$ stress levels instead of Eq. (2), which are given, respectively, as [21]:

$\ln \dot{\varepsilon}=\ln A+n \ln \sigma-\frac{Q}{R T}$,

$\ln \dot{\varepsilon}=\ln A+\beta \sigma-\frac{Q}{R T}$,
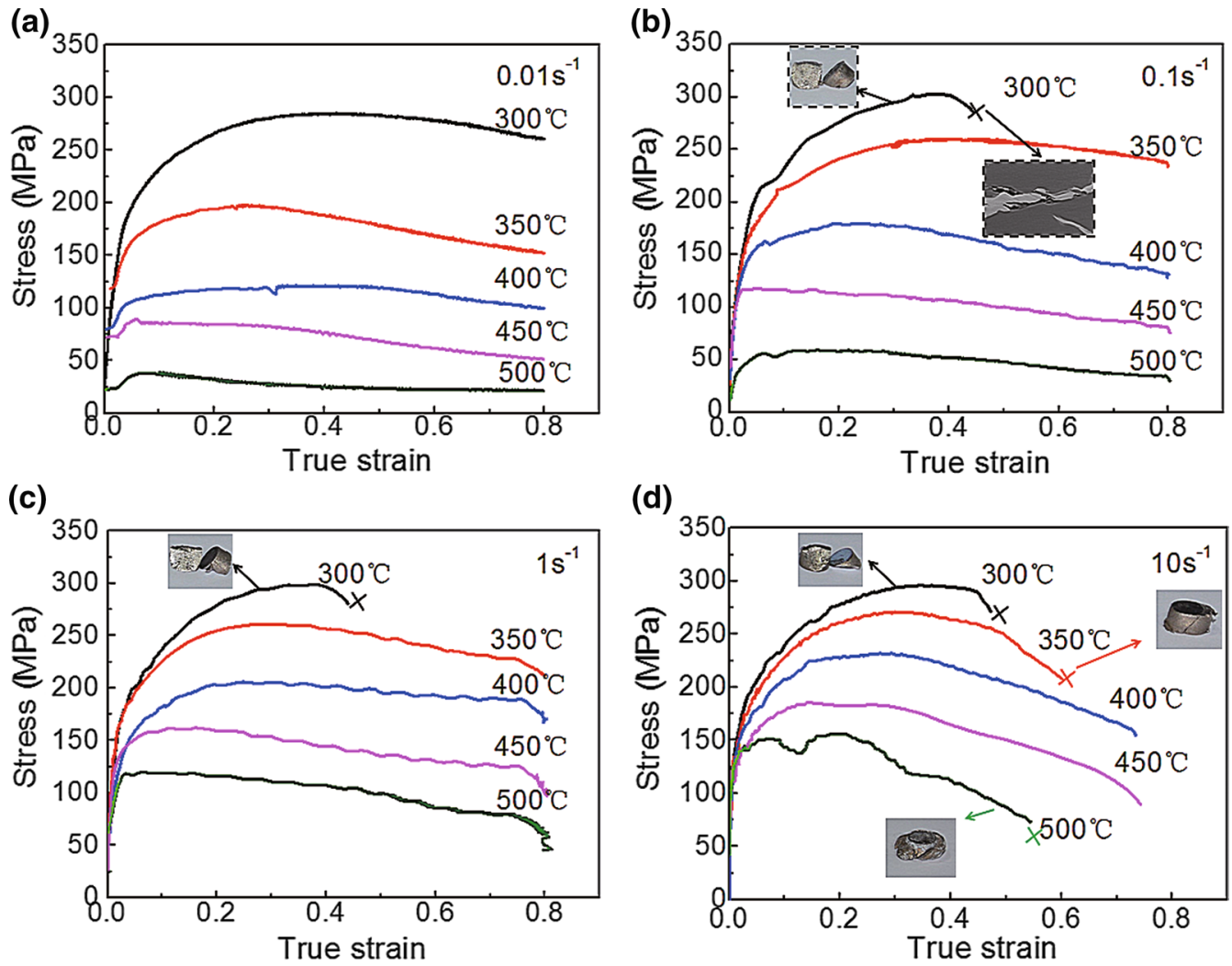

Fig. 6 Ture strain-stress curves of specimens compressed at temperatures of 300-500 ${ }^{\circ} \mathrm{C}$ with a strain rate of a $0.01 \mathrm{~s}^{-1}, \mathbf{b} 0.1 \mathrm{~s}^{-1}$, c $1 \mathrm{~s}^{-1}$, d $10 \mathrm{~s}^{-1}$ 
where $\beta$ is fitting parameter and the $\alpha$ in Eq. (2) can be calculated as $\beta / n$. According to Eqs. (3) and (4), the linear relationships of $\ln \dot{\varepsilon}-\sigma$ and $\ln \dot{\varepsilon}-\ln \sigma$ at different temperatures are fitted as shown in Fig. 7a and b. Their reciprocals of curve slopes of Fig. $7 \mathrm{a}$ are $\mathrm{n}$ with average value being 8.62 and the average value of $\beta$ is determined to be $0.071 \mathrm{MPa}^{-1}$ by the same method. Thus, $\alpha=\beta / n=0.00821 \mathrm{MPa}^{-1}$.

The liner relationships of $\ln \dot{\varepsilon}-\ln [\sinh (\alpha \sigma)]$ and $\ln [\sinh (\alpha \sigma)]-1 / T$ are fitted in Fig. 7c and d, respectively, for the cases, where the $\dot{\varepsilon}$ and $T$ in Eq. (2) are set to be constants. Based on this assumption, the $Q$ can be expressed as:

$Q=R\left[\frac{\partial(\ln (\sinh (\alpha \sigma)))}{\partial(1 / T)}\right]_{\dot{\varepsilon}}\left[\frac{\partial \ln \dot{\varepsilon}}{\partial \ln (\sinh (\alpha \sigma))}\right]_{T}$.

Thus, the average $Q$ value of GWZK 114 alloy is $317.7 \mathrm{~kJ} \mathrm{~mol}^{-1}$ calculated by Eq. (5), which was slightly larger than that of $\mathrm{Mg}-12 \mathrm{Gd}-4.5 \mathrm{Y}-2.0 \mathrm{Zn}-0.4 \mathrm{Zr}$ (wt\%), $287.95 \mathrm{~kJ} \mathrm{~mol}^{-1}$ obtained by Yu et al. [26].

\subsection{Phenomenological DRX Model of As-Homogenized GWZK 114}

Phenomenological DRX model is firstly proposed mainly for the purpose to capture the DRX fraction during plastic
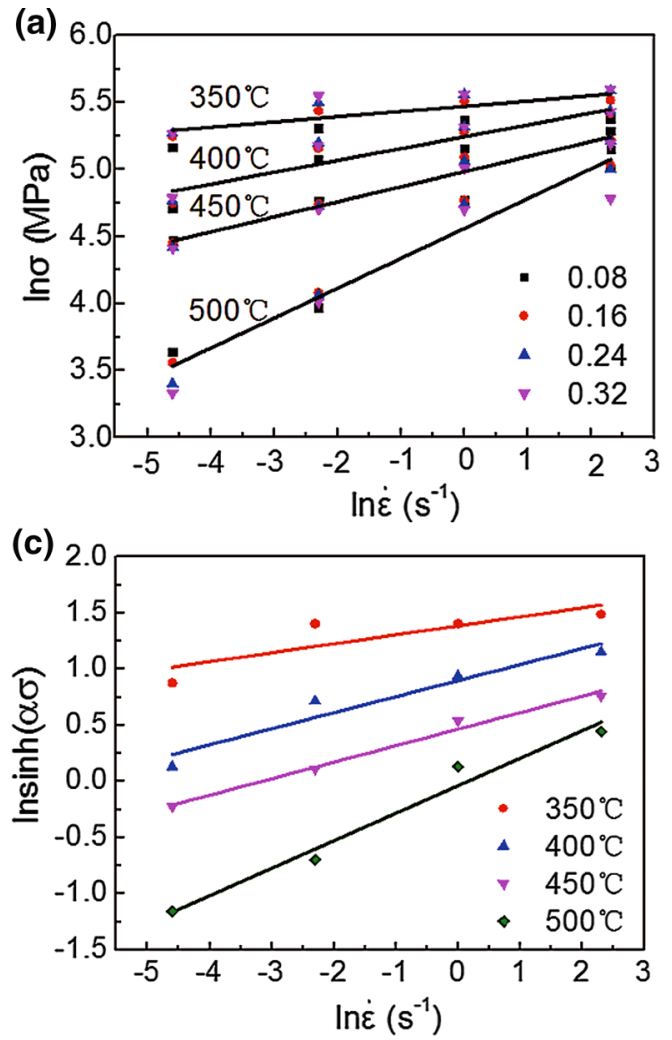

deformation [31, 32]. After widely developed in the past decade years, various formulations of phenomenological DRX model are available [22]. All those models are established on Avrami type equation and the only differences among them are the functional forms and choice of parameters. Considering the characteristics of those DRX models, the following formulation is applied for as-homogenized GWZK 114:

$X_{\mathrm{DRX}}=\left\{1-\exp \left[k\left(\frac{\varepsilon-\varepsilon_{\mathrm{c}}}{\varepsilon^{*}}\right)^{m}\right]\right\}$,

where $X_{\mathrm{DRX}}$ is the fraction of DRX, $\varepsilon_{\mathrm{c}}$ is the critical strain for DRX, $\varepsilon^{*}$ is the strain where maximum rate of strain softening occurs, $k$ and $\mathrm{m}$ are material constants. Moreover, it is found that the $\varepsilon_{\mathrm{c}}$ and $\varepsilon^{*}$ are quantitatively related to deformation temperature and strain rate as [22]:

$\varepsilon_{c}=A_{c} Z^{B_{c}}$,

$\varepsilon^{*}=A^{*} Z^{B^{*}}$,

where $Z=\dot{\varepsilon} \exp (Q / R T)$ is the Zener-Holloman parameter, $A_{c}, B_{c}, A^{*}$ and $B^{*}$ are material constants.

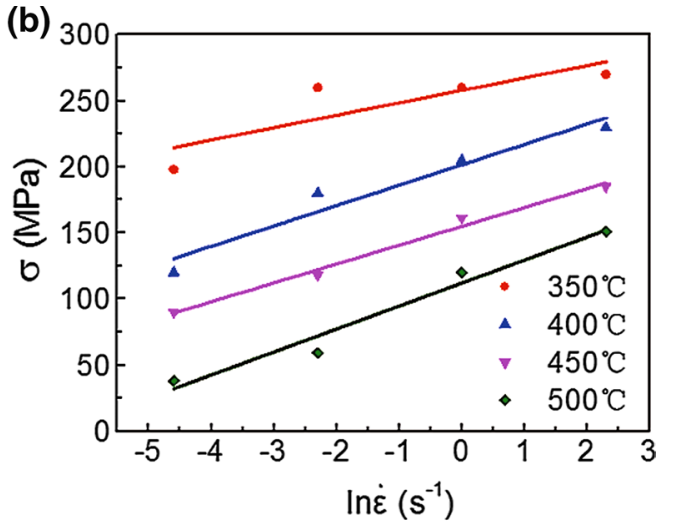

(d)

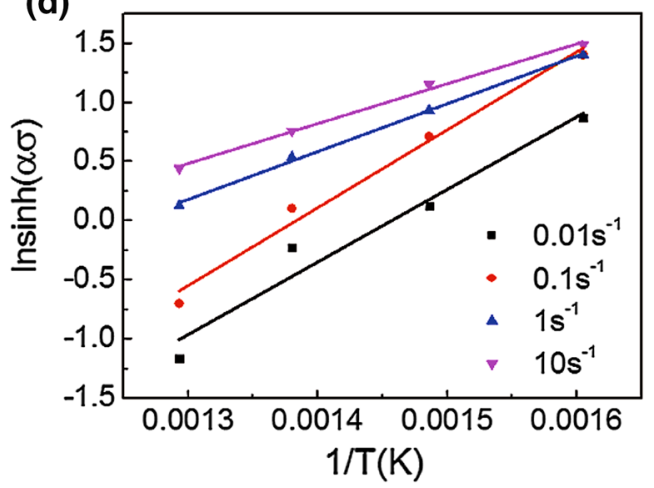

Fig. 7 Relationships among stress, strain rate and temperature: a $\ln |\sigma|$ versus $\ln \dot{\varepsilon} ; \mathbf{b} \sigma$ versus $\ln \dot{\varepsilon} ; \mathbf{c} \ln \sinh (\alpha \sigma)$ versus $\ln \dot{\varepsilon} ; \mathbf{d} \ln \sinh (\alpha \sigma)$ versus $1 / T$ 


\subsubsection{DRX Model Considering Non-uniform Deformation}

During the hot compression of GWZK114 alloy, non-uniform strain is inevitably induced due to the friction between cams and specimen, whereas it is difficult to realize the quantitative measurement of this non-uniformity by experiment methods. Hence, the compression process of cylinder to a nominal strain of 1.2 at $450{ }^{\circ} \mathrm{C}$ is numerically simulated by finite element method (FEM), as shown in Fig. 8. The well-matched outlines between experimental and simulated cylinder verify the accuracy of FEM simulation. In addition, strain evolution of selected points (P1-P6) along radius is presented, where non-uniform strain is obviously observed, especially at later stage of compression. For an instance, the final local strain of central P1 (2.5) is more than three times larger than that of surface P6 (0.75). Only the P5 presents a similar strain with analytical calculation (hollow dots). Corresponding to nominal strains of $0,0.2,0.4,0.6,0.8$, and 1.2 , the local true strains at central region are $0,0.3,0.85$, $1.55,2.06$, and 2.5 .

The simulated strain distribution in Fig. 8 declared that the DRX model to be established by Eq. (6) should consider the non-uniform deformation during compression. Therefore, the DRX fraction acquired from microstructure observation is directly used for getting the material parameters in Eq. (6). In this study, the DRX fraction, $X_{\mathrm{DRX}}$, is statistically analyzed by considering area of DRX grains, $S_{\mathrm{DRX}}$ and area of intergranular phase, $S_{\text {Inter }}$, which can be calculated as:

$X_{\mathrm{DRX}}=\frac{S_{\mathrm{DRX}}}{S_{\mathrm{All}}-S_{\text {Inter }}}$.

Figure 9 gives OM images and DRX grains extracted from EBSD test (Fig. 5) for different strains at $450{ }^{\circ} \mathrm{C}$ and

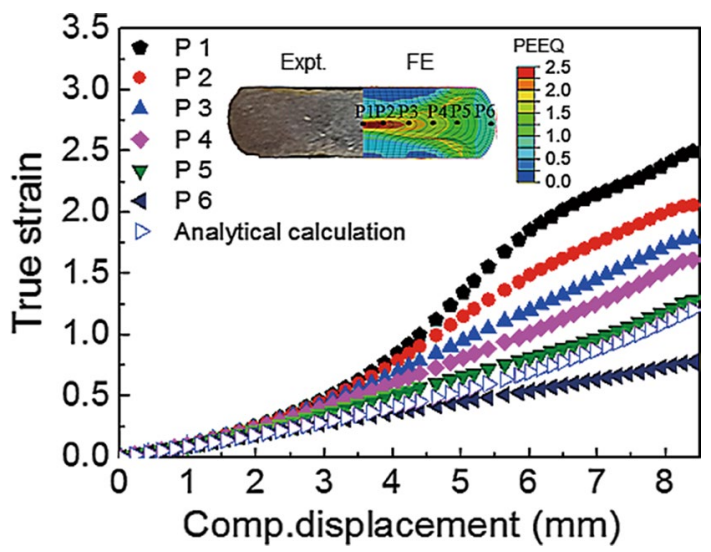

Fig. 8 Strain evolution of selected points (P1-P6) in specimen compressed at $450{ }^{\circ} \mathrm{C}$ to a strain of 1.2 (compression displacement $8.4 \mathrm{~mm}$ ). The analytical strain (hollow dot) was calculated by $\varepsilon=-\ln \left(1-h / H_{0}\right), h$ is height of compressed cylinder and $H_{0}$ is initial height of cylinder, $12 \mathrm{~mm}$
$0.01 \mathrm{~s}^{-1}$. From the OM images (Fig. 9a-c), $S_{\text {DRX, }} S_{\text {Inter }}$ and $S_{\text {All }}$ are obtained, respectively, by Image pro-Plus 6.0 and then $X_{\mathrm{DRX}}$ at local true strains of 0.85, 2.06 and 2.5 can be achieved by Eq. (8). As to EBSD tests (Fig. 9d-f), the same procedure is carried out with HKL channel 5.0, where $S_{\mathrm{DRX}}$ is the area of grains with GOS $<2^{\circ}$ and $S_{\text {Inter }}$ is the area of black non-indexed phase in Fig. 5. The exact values of DRX fractions are listed in Table 2, in which the biggest difference of DRX fraction between OM and EBSD is only 3\%. This indicates that the DRX fractions extracted from OM can be reasonably adopted for establishment of DRX model. Besides, it is noted that the DRX grains induced by PSN mechanism aforementioned have been included in the DRX fraction obtained by this kind of statistics.

Figure 10 shows that the fitted curves with Eq. (6) base on the experimental DRX fractions in Table 2. The final material parameters of DRX model for different deformation conditions can be obtained as shown in Table 3. Slight difference of material parameters exhibits for DRX models based on the DRX fraction of OM and EBSD methods. Thus, the average values of $k$ and $m,-0.50$ and 0.91 , are employed into Eq. (6). The kinetic model of DRX is expressed as:

$X_{\mathrm{DRX}}=\left\{1-\exp \left[-0.5\left(\frac{\varepsilon-\varepsilon_{\mathrm{c}}}{\varepsilon^{*}}\right)^{0.91}\right]\right\}$.

By fitting the $\varepsilon_{\mathrm{c}}$ and $\varepsilon^{*}$ in Table 3 , the $A_{c}, B_{c}, A^{*}$ and $B^{*}$ in Eqs. (7a) and (7b) can be acquired resulting in the following relationship among $\varepsilon_{\mathrm{c}}, \varepsilon^{*}$ and $Z$ :

$\varepsilon_{\mathrm{c}}=0.00216 Z^{0.108}$,

$\varepsilon^{*}=0.0915 Z^{0.052}$.

Figure 11a compares the measured and predicted DRX fractions under various compression conditions with a fixed local strain of 2.06. Their good match verifies that the established DRX model can well predict the DRX fraction of GWZK114 deformed at temperature range of $450-500{ }^{\circ} \mathrm{C}$. Given the prior discussion (Fig. 4), LPSO kinking is rarely involved in the plastic deformation during this temperature range. Besides the DRX model composed of Eqs. (9)-(10), another DRX model without considering the non-uniform strain can also be formulated on the nominal strain via the same way. The specific equations are no longer presented for simplify. Meanwhile, the DRX fractions of as-homogenized GWZK114 after different passes of RUE are available from the work of Du et al. [27], and it provides the possibility to compares these two models at a larger strain $(\bar{\varepsilon}=6.75)$. In Fig. 11b, comparison between DRX fractions predicted by both models and measured ones of RUE is performed. The results reveal that the DRX model including effect of non-uniform strain (solid lines) can reasonably depict the evolution of DRX fraction during RUE. The existing difference is probably caused by 

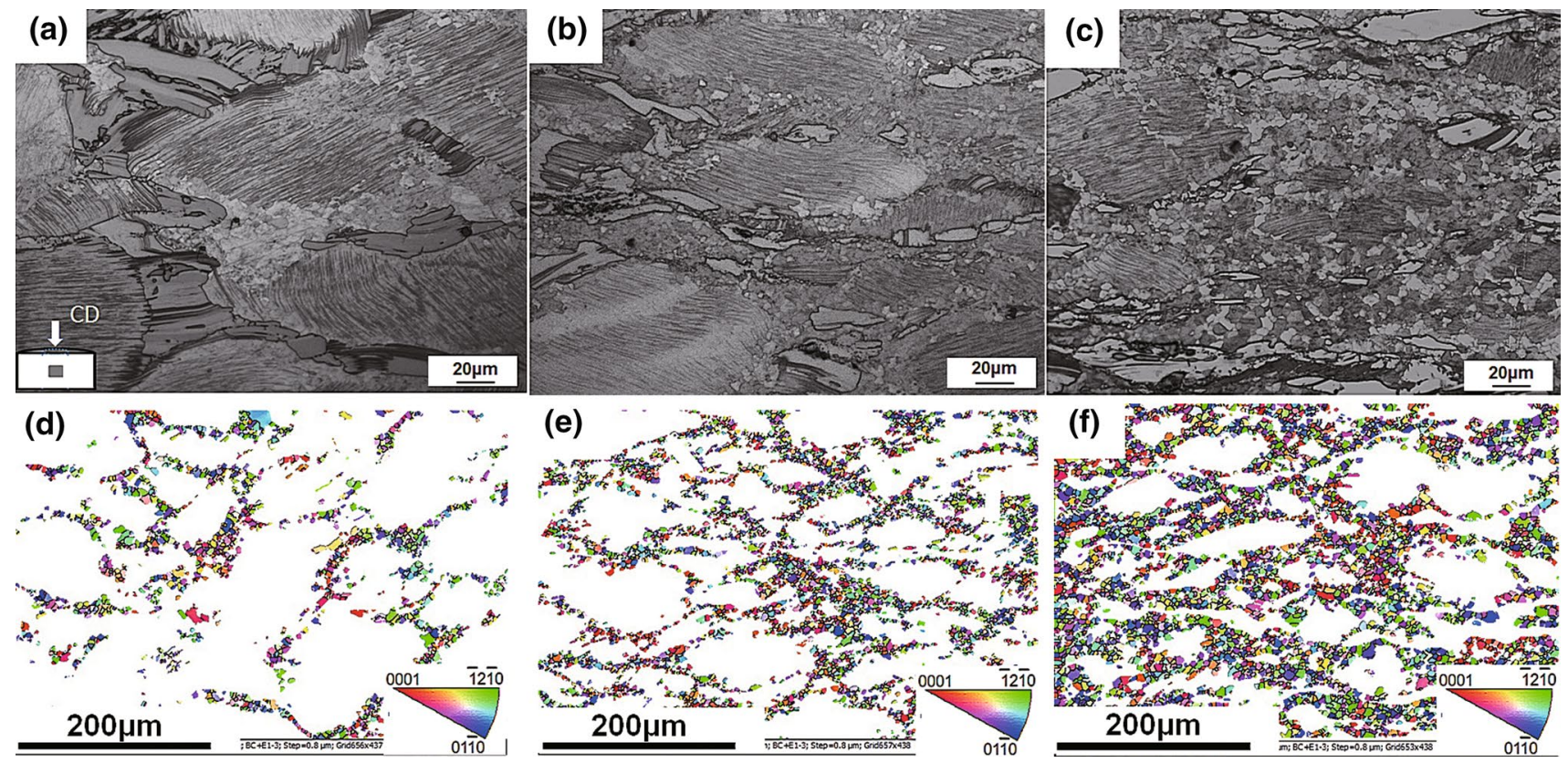

Fig. 9 Microstructure of specimens deformed at $450{ }^{\circ} \mathrm{C}$ and $0.01 \mathrm{~s}^{-1}$ : OM images at true strains a 0.4 (0.85); b 0.8 (2.06) and c 1.2 (2.5); DRX grains extracted from EBSD tests in Fig. 5; $\mathbf{d}$ true strain 0.4 (0.85); e true strain 0.8 (2.06); $\mathbf{f}$ true strain 1.2 (2.5). The strains in the brackets are the local true strain

Table 2 DRX fractions obtained from OM and EBSD under different strains at $450{ }^{\circ} \mathrm{C}$ and $0.01 / 1 \mathrm{~s}^{-1}$

\begin{tabular}{lllllll}
\hline$X_{\text {DRX }}$ & \multicolumn{7}{l}{ Local true strain } \\
\cline { 2 - 6 } & 0 & 0.3 & 0.85 & 1.55 & 2.06 & 2.5 \\
\hline $450{ }^{\circ} \mathrm{C}-0.01 \mathrm{~s}^{-1}(\mathrm{OM})$ & 0 & 0 & 0.22 & 0.40 & 0.45 & 0.65 \\
$450{ }^{\circ} \mathrm{C}-0.01 \mathrm{~s}^{-1}(\mathrm{EBSD})$ & - & - & 0.19 & - & 0.44 & 0.62 \\
$450{ }^{\circ} \mathrm{C}-1 \mathrm{~s}^{-1}(\mathrm{OM})$ & 0 & 0 & 0.10 & 0.25 & 0.37 & 0.51 \\
\hline
\end{tabular}

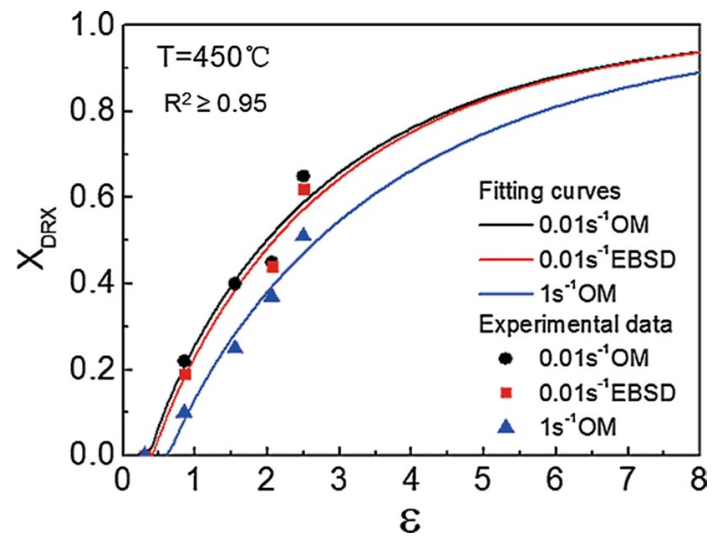

Fig. 10 Fitted curves of DRX model based on experimental data at $450{ }^{\circ} \mathrm{C}$ with strain rates of 0.01 and $1 \mathrm{~s}^{-1}$

decrease in dislocation density due to reheat treatment between each pass of RUE [27], which could reduce the kinetic energy for DRX and led to a lower fraction of DRX. In contrast, the DRX model without considering the
Table 3 DRX model parameters obtained by fitting DRX fractions of $\mathrm{OM}$ and EBSD at $450{ }^{\circ} \mathrm{C}$ and $0.01 / 1 \mathrm{~s}^{-1}$

\begin{tabular}{lllll}
\hline Conditions & \multicolumn{4}{l}{ Parameters of DRX model } \\
\cline { 2 - 5 } & $\varepsilon_{\mathrm{c}}$ & $\varepsilon^{*}$ & $K$ & $m$ \\
\hline $450{ }^{\circ} \mathrm{C}-0.01 \mathrm{~s}^{-1}(\mathrm{OM})$ & 0.368 & 1.101 & -0.490 & 0.90 \\
$450{ }^{\circ} \mathrm{C}-0.01 \mathrm{~s}^{-1}(\mathrm{EBSD})$ & 0.415 & 1.204 & -0.512 & 0.92 \\
$450{ }^{\circ} \mathrm{C}-1 \mathrm{~s}^{-1}(\mathrm{OM})$ & 0.640 & 1.421 & -0.498 & 0.91 \\
\hline
\end{tabular}

non-uniform strain displays a totally deflected prediction (dash lines). This indicates that DRX model considering non-uniform strain can be applied to obtain DRX fractions of thermal process with large plastic strain, for instance, RUE.

\subsubsection{DRX Model Considering LPSO Kinking}

In order to further validate the effectiveness of DRX model [Eqs. (9) and (10)], DRX fractions of the low-temperature compression $\left(350-450{ }^{\circ} \mathrm{C}\right)$ are also evaluated, in which 

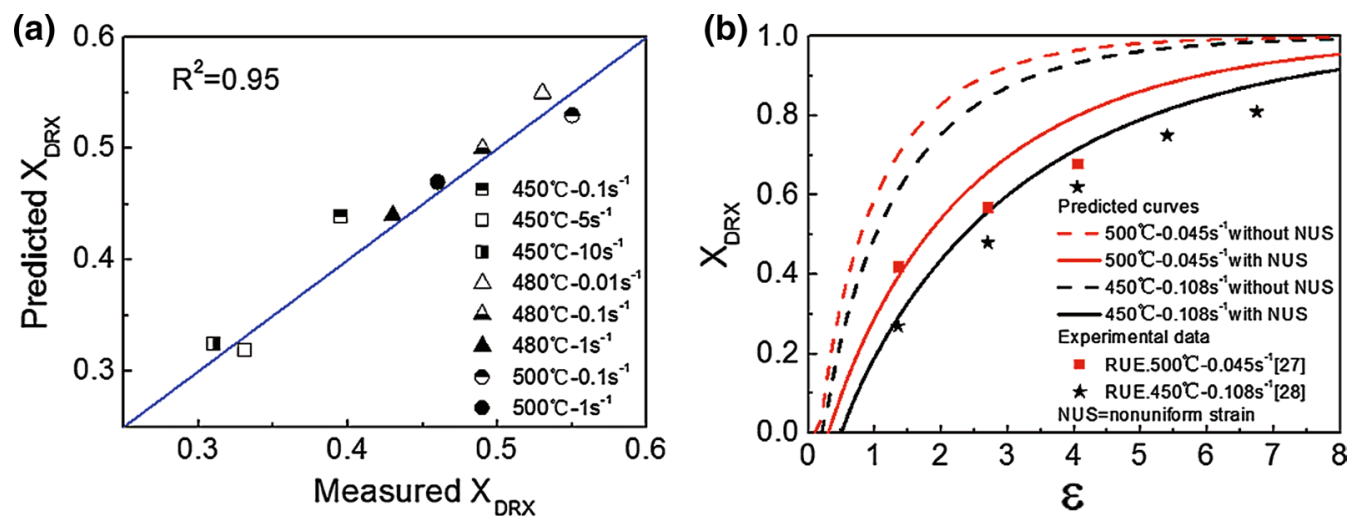

Fig. 11 Comparison between measured and predicted DRX fractions of: a various compression conditions at a local strain of 2.06 (nominal strain 0.8); b RUE without (dash lines) and with (solid line) considering non-uniform strain. The mean strain rate of RUE process is calculated through Eq. (6) in the Ref. [33]. More parameters of RUE process, such as plastic strain per pass, extrusion speed, are referred to the references [27]

14H-LPSO kinking is deeply involved. Figure 12a illustrates the DRX fractions under $400{ }^{\circ} \mathrm{C}$ with strain rate being $0.01-1 \mathrm{~s}^{-1}$. The results suggest that although the DRX model previously established have considered the non-uniform strain effect, it still makes a much higher prediction of DRX fractions than those of experimental measurement. In other words, the DRX model should consider the inhibited effect of LPSO kinking on kinetic of DRX at a low deformation temperature. At the same time, the evolution of kinking angles of LPSO phase with temperatures and strain rates are also presented in Fig. $12 \mathrm{~b}$. At $350^{\circ} \mathrm{C}$ and $400{ }^{\circ} \mathrm{C}$, kinking angles of $14 \mathrm{H}$-LPSO obviously increase with strain rate being raised from 0.01 to $1 \mathrm{~s}^{-1}$. However, they stay to be almost same $\left(\sim 10^{\circ}\right)$ in $450^{\circ} \mathrm{C}$ irrespective with strain rates. The higher kinking angle is, the more strain is accommodated, which means a larger restricted impact on DRX behavior.
For the purpose to model the effect of LPSO kinking, an enhanced DRX model is proposed. On the basics of Eq. (9), an extra item, $f(T, \dot{\varepsilon})$, is introduced to capture the evolving role of LPSO kinking with temperature and strain rate as shown in Figs. 5 and 12b. The final formulation of this enhanced DRX model can be expressed as:

$$
\begin{aligned}
& X_{\mathrm{DRX}}=\left\{1-\exp \left[-0.5\left(\frac{\varepsilon-\varepsilon_{\mathrm{c}}}{\varepsilon^{*}}\right)^{0.91}\right]\right\} f(T, \dot{\varepsilon}), \\
& f(T, \dot{\varepsilon})=\left(\frac{T}{T_{\mathrm{c}}}-1\right)^{n}, \quad n=a \dot{\varepsilon}^{b},
\end{aligned}
$$

where $a$ and $b$ are material constants. $T_{\mathrm{c}}$ is the critical recrystallization temperature of recrystallization taking a value range of (0.35-0.4) $T_{\mathrm{m}}$. The melting temperature $T_{\mathrm{m}}$ of pure
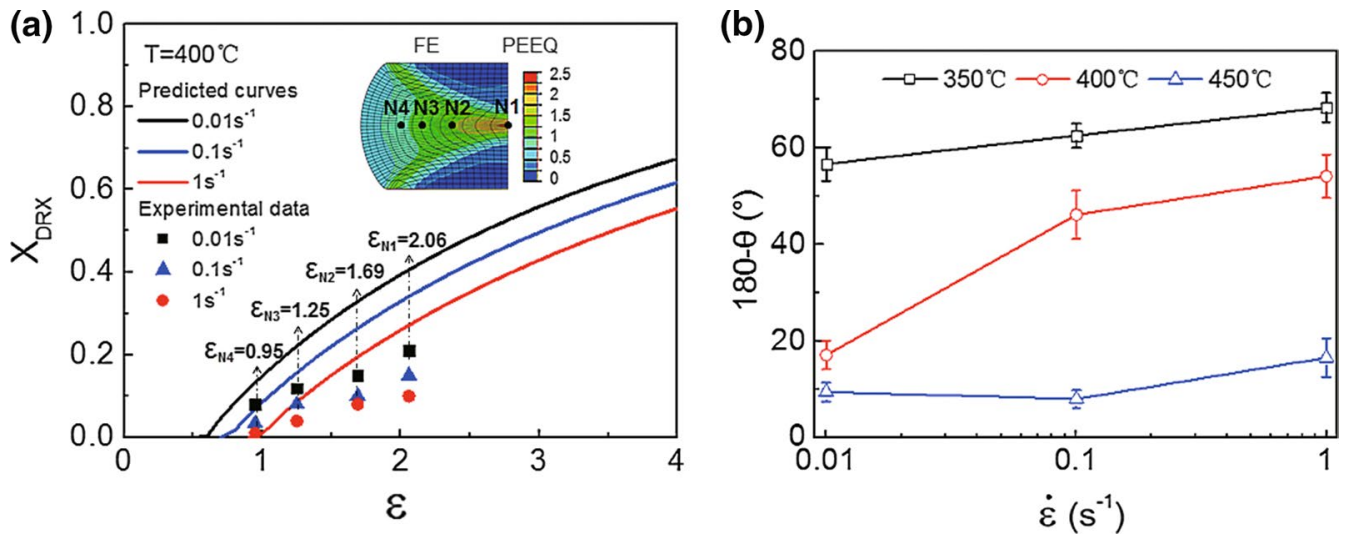

Fig. 12 a Comparison between measured and predicted DRX fractions [Eqs. (9) and (10)] of $400{ }^{\circ} \mathrm{C}-0.01-1 \mathrm{~s}^{-1}$; b kinking angles of $14 \mathrm{H}-\mathrm{LPSO}$ phase under different compression conditions $\left(350-450{ }^{\circ} \mathrm{C}\right.$ and $\left.0.01-1 \mathrm{~s}^{-1}\right)$. DRX fractions at $\mathrm{N} 1-\mathrm{N} 4$ were achieved by OM observation and their corresponding values of strain are determined by FEM 
magnesium is $648{ }^{\circ} \mathrm{C}$ [34]. Thus, $T_{\mathrm{c}}$ is set to be $0.35 T_{\mathrm{m}}$, $226.8^{\circ} \mathrm{C}$ in this study.

Figure 13a illustrates the detailed process to build the relation between $n$ and $\dot{\varepsilon}$ based on measured DRX fractions at $400{ }^{\circ} \mathrm{C}$ with strain rate being $0.01 \mathrm{~s}^{-1}, 0.1 \mathrm{~s}^{-1}$ and $1 \mathrm{~s}^{-1}$. By fitting those data with Eq. (11a), three different $n$ are available to be $2.61,3.15$ and 3.83. With another fitting by Eq. (11b), the relation between $\mathrm{n}$ and $\dot{\varepsilon}$ can be finally formulated as:

$n=3.82(\dot{\varepsilon})^{0.0834}$.

By submitting Eq. (12) into Eq. (11), the enhanced DRX model considering LPSO kinking can be established as:

$X_{\mathrm{DRX}}=\left\{1-\exp \left[-0.5\left(\frac{\varepsilon-\varepsilon_{\mathrm{c}}}{\varepsilon^{*}}\right)^{0.91}\right]\right\} f(T, \dot{\varepsilon})$,

$f(T, \dot{\varepsilon})=\left(\frac{T}{226.8}-1\right)^{n}, \quad n=3.82(\dot{\varepsilon})^{0.0834}$,

Using Eq. (13), the DRX fractions at $350{ }^{\circ} \mathrm{C}$ and $0.01 \mathrm{~s}^{-1}$ are well predicted as shown in Fig. 13a (dash line). Again, in Fig. 13b the DRX fractions of RUE process at $420{ }^{\circ} \mathrm{C}$ and $0.01 \mathrm{~s}^{-1}$ are calculated by DRX models without LPSO kinking [Eq. (10)] and with LPSO kinking [Eq. (13)]. After compression, only the model with LPSO kinking gives a very good agreement with experimental data of RUE process [28], whereas the one without LSPO kinking significantly overestimate the DRX fraction. Therefore, it can be believed that the enhanced DRX model with LPSO kinking [Eq. (13)] can well track the DRX fraction of GWZK 114 alloy under deformation temperature with LPSO kinking being deeply involved $\left(300-450{ }^{\circ} \mathrm{C}\right)$.

Figure $13 \mathrm{c}$ further analyzes the evolution of $f$ values with deformation temperatures and strain rates. Corresponding to Fig. 12b, a smaller value of $f$ appears for deformation condition with a lower temperature and higher strain rate for its larger kinking angle. This means a larger influence of LPSO kinking on the DRX behavior. With the temperature decreasing from 450 to $350{ }^{\circ} \mathrm{C}$ at $0.1 \mathrm{~s}^{-1}$, the value of $f$ reduces from 0.972 to 0.150 , where the kinking angle increased from $7.9^{\circ}$ to $62.6^{\circ}$ (Figs. 5, 12b). Under a fixed deformation temperature, $f$ decreases gradually with increasing strain rates increasing. This is also consistent with evolution of kinking angles, whereas the values of $f$ under $450{ }^{\circ} \mathrm{C}$ just change from 0.984 to 0.960 with strain rate shifting from 0.01 to $1 \mathrm{~s}^{-1}$ attributed to their low and nearly constant kinking angles $\left(\sim 10^{\circ}\right)$. All these consistencies between calculation of $f$ and kinking angles of LPSO phase declare that the item $f$ is reliable and robust to capture the effect of LPSO kinking on DRX behavior.

\subsection{Evolution of DRX Grain Size and Its Model}

Figure 14 systematically presents the evolution of DRX grain size with changing the temperatures, strain rate and strain levels individually. As shown in Fig. 14a, the size of DRX grains is really sensitive to the deformation temperature. Under a constant strain rate of $0.1 \mathrm{~s}^{-1}$, the size of DRX grain greatly increases from 0.30 to $4.8 \mu \mathrm{m}$ with the deformation temperature changing form to 350 to $500{ }^{\circ} \mathrm{C}$. Also, it is found in Fig. 14b that strain rate plays an important role in the evolution of size of DRX grains, whereas distinctive with the monotonic relationship with temperature, the DRX grain size firstly decreases with strain rate ranging from 0.01 to $1 \mathrm{~s}^{-1}$ and then increase from 1 to $10 \mathrm{~s}^{-1}$. Further, as shown in Fig. 14c, the grain size is almost independent with strain levels.

On the other hand, numbers of researches have pointed out that the grain sizes of DRX usually possess a relationship with $Z$ given as [31] [32]:

$d_{R-\text { grain }}=C Z^{m}$,

where $d_{R \text {-grain }}$ is the average size of DRX grain, $C$ and $m$ are constants, which can be determined by fitting the measured (a)

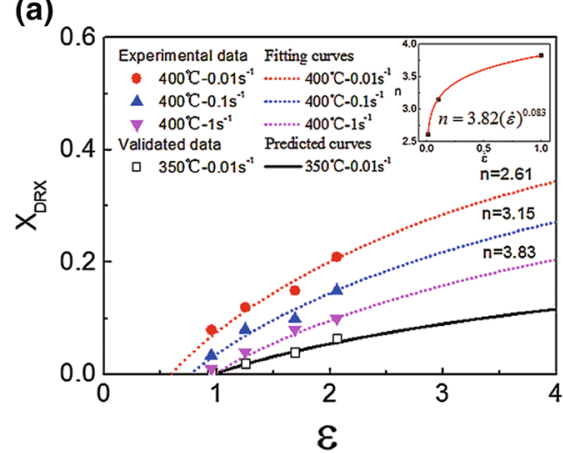

(b)

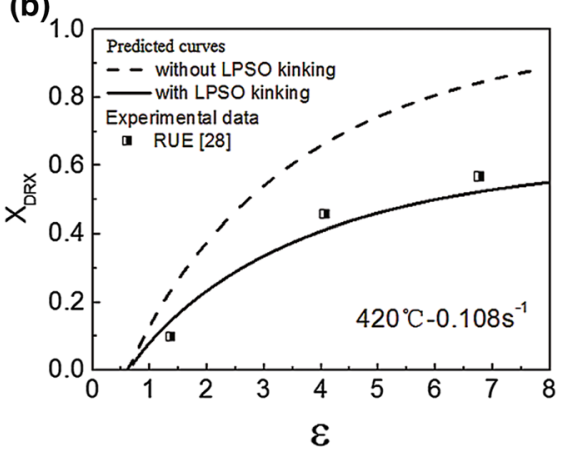

(c)

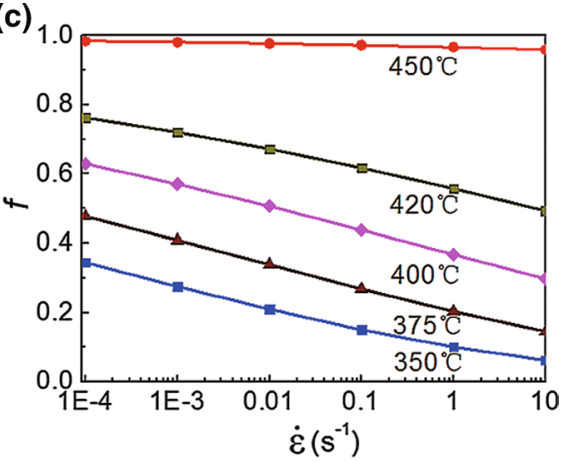

Fig. 13 a Relation between $\mathrm{n}$ and $\dot{\varepsilon}$ considering LPSO kinking and its validation by data of $400{ }^{\circ} \mathrm{C}$, $\mathbf{b}$ predicted DRX fractions of RUE process by DRX model without and with LPSO kinking at $420{ }^{\circ} \mathrm{C}-0.108 \mathrm{~s}^{-1}$ [28]; $\mathbf{c}$ evolution of $f$ values with different deformation temperatures and strain rates 
(a)

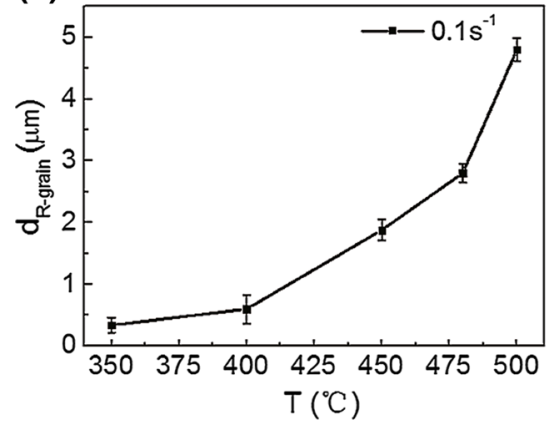

(b)

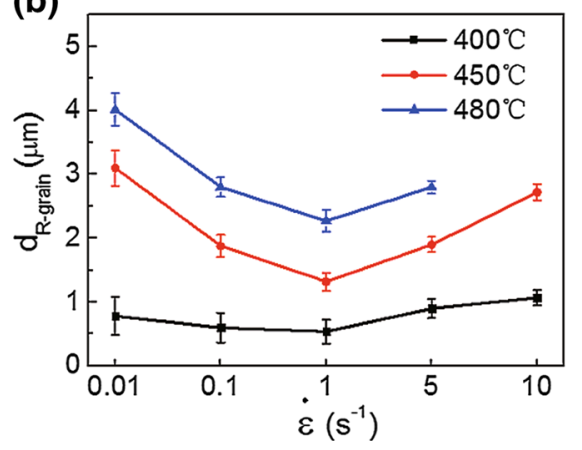

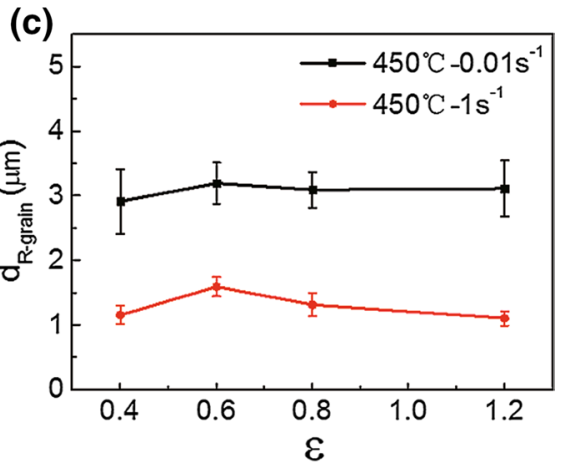

Fig. 14 Evolution of DRX grain size with a deformation temperatures at $0.1 \mathrm{~s}^{-1}$; b strain rates at temperatures of $400{ }^{\circ} \mathrm{C}, 450{ }^{\circ} \mathrm{C}$ and $480{ }^{\circ} \mathrm{C}$, c compression strains at $450{ }^{\circ} \mathrm{C}$ with strain rate being $0.01 \mathrm{~s}^{-1}$ and $1 \mathrm{~s}^{-1}$

values of grain size shown in Fig. 15a. As a result, the model of DRX grain size can be rewritten as:

$d_{R-\text { grain }}=255250 Z^{-0.235}$.

Figure $15 \mathrm{~b}$ displays the consequence of model validation for Eq. (15) with sizes of DRX grain at $480{ }^{\circ} \mathrm{C}$ with a low strain rate of $0.01-1 \mathrm{~s}^{-1}$ and $400{ }^{\circ} \mathrm{C} / 450{ }^{\circ} \mathrm{C}$ with a high strain rate of $5 \mathrm{~s}^{-1}$ and $10 \mathrm{~s}^{-1}$. The model gives a good prediction for DRX grain sizes under low strain rate range of $0.01-1 \mathrm{~s}^{-1}$. Meanwhile, the model also predicts the results of $420{ }^{\circ} \mathrm{C}-0.108 \mathrm{~s}^{-1}, 450{ }^{\circ} \mathrm{C}-0.108 \mathrm{~s}^{-1}, 480{ }^{\circ} \mathrm{C}-0.108 \mathrm{~s}^{-1}$ and $500{ }^{\circ} \mathrm{C}-0.045 \mathrm{~s}^{-1}$ at RUE [27], but due to reheat treatment between each pass of RUE so that the results were bigger than prediction. However, it is inapplicable for the cases of high strain rates $\left(5 \mathrm{~s}^{-1}\right.$ and $\left.10 \mathrm{~s}^{-1}\right)$, where big differences exist between experimental measurement and prediction (solid points). As shown in Fig. 14, deformation temperature and strain rate are two essential factors to decide the size of DRX grain. Generally, a larger size at higher temperature is expected because of the higher growth rate of DRX grain. Relatively, a higher strain rate usually produces a smaller grain size attributed to a short time for grain growth for a certain strain. Hence, the unconventional sizes of DRX grain at high strain rates of $5 \mathrm{~s}^{-1}$ and $10 \mathrm{~s}^{-1}$ in Figs. $14 \mathrm{~b}$ and $15 \mathrm{~b}$ are probably caused by the change in temperature.

The increase in temperature produced by plastic work can be calculated as [35]:

$\Delta T=\frac{\eta \int_{0}^{\varepsilon_{\mathrm{f}}} \sigma \mathrm{d} \varepsilon}{\rho C_{v}}$

where $\eta$ is the coefficient of conversion between plastic work and deformation heat, taken as 0.9 [35], $\varepsilon_{\mathrm{f}}$ is final plastic strain obtained by averaging the all the local true strains, $\rho$ is the density of GWZK 114 alloy $\left(1.74 \mathrm{~g} / \mathrm{cm}^{3}\right)$ and $C_{v}$ is the specific heat of the alloy [1.55 $\mathrm{kJ} \mathrm{kg}^{-1} \mathrm{~K}^{-1}$ ] [36]. After calculation with Eq. (16), the temperature rising at $400{ }^{\circ} \mathrm{C}$ with $5 \mathrm{~s}^{-1}$ and $10 \mathrm{~s}^{-1}$ is $59^{\circ} \mathrm{C}$ and $84^{\circ} \mathrm{C}$, respectively. It is $57^{\circ} \mathrm{C}$ and $81{ }^{\circ} \mathrm{C}$ for $450{ }^{\circ} \mathrm{C}$ with $5 \mathrm{~s}^{-1}$ and $10 \mathrm{~s}^{-1}$. Submitting the increase in temperature into size model of DRX grain [Eq. (15)], the new data (dot points in Fig. 15) are located into an error range $\pm 10 \%$ of model prediction.
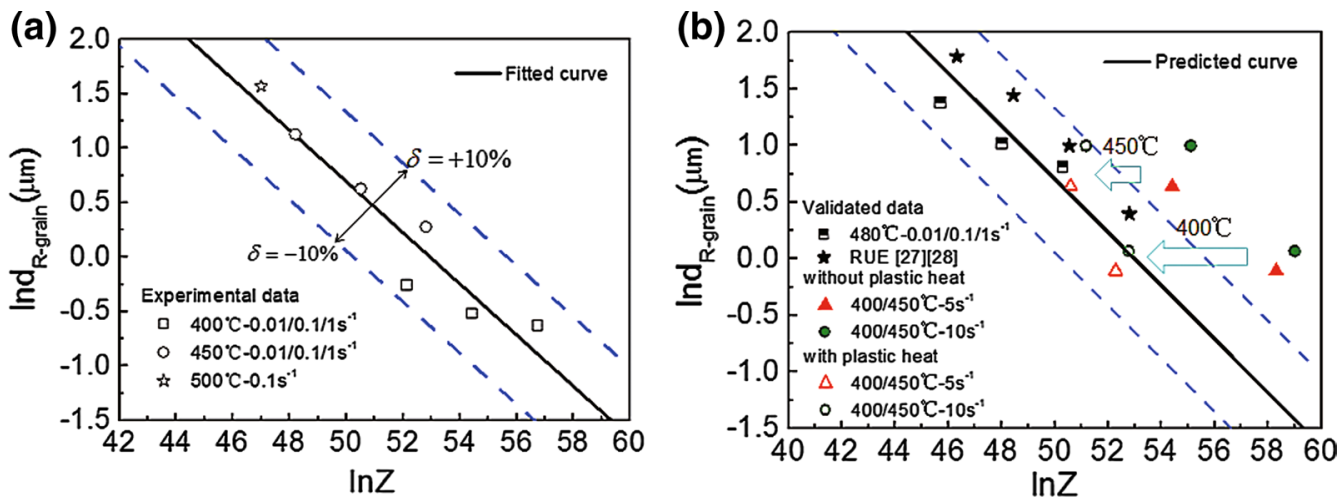

Fig. 15 a Fitting curve of experimental data; $\mathbf{b}$ validation for model of DRX grain size 


\section{Conclusions}

The DRX behavior of as-homogenized GWZK114 alloy during hot compression was systematically investigated and phenomenologically modeled. The conclusions can be obtained as follows:

1. Kinking of lamella-shaped 14H-LPSO phase plays an evolving role in the DRX behavior. At $350-450{ }^{\circ} \mathrm{C}$, 14H-LPSO kinking mainly presents a restricted effect on DRX behavior for its strain accommodation. Moreover, this effect is enlarged by larger kinking angle at a lower temperature and a higher strain. At $500{ }^{\circ} \mathrm{C}, 14 \mathrm{H}-\mathrm{LPSO}$ phase is no longer kinked and DRX is dominated.

2. The deformation activation energy $Q$ of as-homogenized GWZK 114 alloy is determined to be $317.7 \mathrm{~kJ} \mathrm{~mol}^{-1}$. For temperature range of $450-500{ }^{\circ} \mathrm{C}$ with a neglected LPSO kinking, a phenomenological DRX model considering the non-uniform strain during compression was established as:

$$
\begin{aligned}
X_{\mathrm{DRX}} & =\left\{1-\exp \left[-0.5\left(\frac{\varepsilon-\varepsilon_{\mathrm{c}}}{\varepsilon^{*}}\right)^{0.91}\right]\right\} . \\
\varepsilon_{c} & =0.00216 Z^{0.108}, \quad \varepsilon^{*}=0.0915 Z^{0.052}
\end{aligned}
$$

The good agreement between DRX fractions of experiment and perdition indicates that the established models can well account for effect of non-uniform compressive strain.

3. As to $350-450{ }^{\circ} \mathrm{C}$ : an enhanced DRX model is proposed to account for the restricted effect of 14H-LPSO kinking as:

$X_{\mathrm{DRX}}=\left\{1-\exp \left[-0.5\left(\frac{\varepsilon-\varepsilon_{\mathrm{c}}}{\varepsilon^{*}}\right)^{0.91}\right]\right\} f(T, \dot{\varepsilon})$,

$f(T, \dot{\varepsilon})=\left(\frac{T}{226.8}-1\right)^{n}, \quad n=3.82(\dot{\varepsilon})^{0.0834}$.

It is found that this new model can simultaneously capture influence of non-uniform strain and LPSO kinking.

4. Besides, a model of DRX grain size with good ability of prediction was obtained as:

$d_{R-\text { grain }}=255250 Z^{-0.235}$.

\section{References}

[1] T.M. Pollock, Science 328, 986-987 (2010)

[2] J.W. Dai, X.B. Zhang, Y. Fei, Z.Z. Wang, H.M. Sui, Acta Metall. Sin. (Engl. Lett.) 31, 865-872 (2018)

[3] K. Hagihara, A. Kinoshita, Y. Yamasaki, M. Yamasaki, Y. Kawamura, Mater. Sci. Eng. A 560, 71-79 (2013)
[4] M. Yamasaki, Y. Kawamura, Scr. Mater. 60, 264-267 (2009)

[5] T. Itoi, K. Takahashi, H. Moriyama, H. Moriyama, M. Hirohashi, Scr. Mater. 59, 1155-1158 (2008)

[6] Y. Kawamura, T. Kasahara, S. Izumi, M. Yamasaki, Scr. Mater. 55, 453-456 (2006)

[7] K. Hagihara, A. Kinoshita, Y. Sugino, M. Yamasaki, Y. Kawamura, H.Y. Yasuda, Y. Umakoshi, Acta Mater. 58, 6282-6293 (2010)

[8] K. Hagihara, M. Honnami, R. Matsumoto, Y. Fukusumi, H. Izuno, M. Yamasaki, T. Okamoto, T. Nakano, Y. Kawamura, Mater. Trans. 56, 943-951 (2015)

[9] X.H. Shao, Z.Q. Yang, X.L. Ma, Acta Mater. 58, 4760-4771 (2010)

[10] E. Oñorbe, G. Garcés, P. Pérez, P. Adeva, J. Alloys Compd. 47, 1085-1093 (2012)

[11] C. Xu, T. Nakata, X. Qiao, M. Zheng, K. Wu, S. Kamado, Sci Rep. 7, $40846(2017)$

[12] D. Zhang, Z. Tan, Q. Huo, Z. Xiao, Z. Fang, X. Yang, Mater. Sci. Eng. A 715, 389-403 (2018)

[13] B.J. Lv, J. Peng, Y. Peng, A.T. Tang, F.S. Pan, Mater. Sci. Eng. A 579, 209-216 (2013)

[14] W. Yuan, S.K. Panigrahi, J.Q. Su, R.S. Mishra, Scr. Mater. 65, 994 997 (2011)

[15] J.A. Del Valle, F. Carreño, O.A. Ruano, Acta Mater. 54, 4247-4259 (2006)

[16] M.R. Barnett, Z. Keshavarz, A.G. Beer, D. Atwell, Acta Mater. 52, 5093-5103 (2004)

[17] X.H. Huang, K. Suzuki, Y. Chino, M. Mabuchi, J. Alloys Compd. 632, 94-102 (2015)

[18] T. Homma, N. Kunito, S. Kamado, Scr. Mater. 61, 644-647 (2009)

[19] I. Schindler, P. Kawulok, E. Hadasik, D. Kuc, JMEPEG 22, 890-897 (2013)

[20] Z. Yang, Y.C. Guo, J.P. Li, F. He, F. Xia, M.X. Liang, Mater. Sci. Eng. A 485, 487-491 (2008)

[21] G.Z. Quan, Y. Shi, Y.X. Wang, B.S. Kang, W.T. Ku, W.J. Song, Mater. Sci. Eng. A 528, 8051-8059 (2011)

[22] J. Liu, Z.S. Cui, L.Q. Ruan, Mater. Sci. Eng. A 529, 300-310 (2011)

[23] E.I. Poliak, J.J. Jonas, Acta Mater. 44, 127-136 (1996)

[24] A. Najafizadeh, J.J. Jonas, ISIJ Int. 46, 1679-1684 (2006)

[25] B.J. Lv, J. Peng, L.L. Zhu, Y.J. Wang, Mater. Sci. Eng. A 599, 150$159(2014)$

[26] J. Yu, Z. Zhang, Q. Wang, X. Yin, J. Cui, H. Qi, J. Alloys Compd. 704, 382-389 (2017)

[27] G. Zhang, Z. Zhang, Y. Du, Z. Yan, X. Che, Materials 11, 2092 (2018)

[28] Y. Du, Dissertation, North University of China, 2018 (in Chinese)

[29] C.J. Wang, Z.G. Zhou, A. Holmqvist, H. Zhang, Y. Li, G. Adell, X.F. Sun, AIMM 17, 530-535 (2009)

[30] X.J. Zhou, C.M. Liu, Y.H. Gao, S.N. Jiang, X.Z. Han, Z.Y. Chen, Metall. Mater. Trans. A 48, 3060-3072 (2017)

[31] C.M. Sellars, Mater. Sci. Technol. 6, 1072-1081 (1990)

[32] C.M. Sellars, Metal Sci. 13, 187-194 (1979)

[33] T. Chandra, J.J. Jonas, Metall. Trans. 1, 2079-2082 (1970)

[34] D.R. Askeland, W.J. Wright, Essentials of Materials Science \& Engineering (Cengage Learning, Singapore, 2013), p. 233

[35] J. Su, M. Sanjari, A.S.H. Kabir, I.H. Jung, J.J. Jonas, S. Yue, H. Utsunomiya, Mater. Sci. Eng. A 636, 582-592 (2015)

[36] C.J. Chen, Q.D. Wang, D.D. Yin, J. Alloys Compd. 487, 560-563 (2009) 